\title{
FISH studies in a patient with sporadic aniridia and $\mathrm{t}(7 ; 11)(\mathrm{q} 31.2 ; \mathrm{p} 13)$
}

\author{
John A Crolla, Ian Cross, Neil Atkey, Michael Wright, Christine A Oley
}

Wessex Regional

Genetics Laboratory, Salisbury District

Wiltshire SP2 8BJ, UK

J A Crolla

Northern Region

Genetics Service,

University of

Newcastle upon Tyne,

19/20 Claremont Place,

NE2 4AA, UK

I Cross

N Atkey

M Wright

C A Oley

Correspondence to: Mr Crolla.

Received 31 July 1995

Revised version accepted

for publication

7 September 1995 Hospital, Salisbury,

Newcastle upon Tyne

\begin{abstract}
A 2 year old female presenting with bilateral sporadic aniridia was found to have an apparently balanced reciprocal translocation with a chromosome 11 breakpoint within band p13. Fluorescence in situ hybridisation (FISH) studies with distal 11 13 specific cosmids showed that the chromosome 11 breakpoint lay between the aniridia (PAX6) locus and a region approximately $100 \mathrm{~kb}$ distal to PAX6 defined by the cosmid FO2121. Although this patient did not have a detectable deletion within PAX6, her aniridia may have resulted from a disruption of the distal chromatin domain containing either enhancers or regulators for PAX6. This case may therefore be another example of aniridia caused by a position effect as recently described in two familial aniridia patients in which the phenotype cosegregated with chromosome abnormalities with $11 \mathrm{p} 13$ breakpoints.

(f Med Genet 1996;33:66-68)
\end{abstract}

Key words: FISH; aniridia; position effect.

Aniridia is a rare congenital absence of the iris affecting approximately 1 in 50000 newborns ${ }^{1}$ and can present in isolation or more rarely as part of the contiguous gene syndrome known by the acronym WAGR (Wilms' tumour, ani-
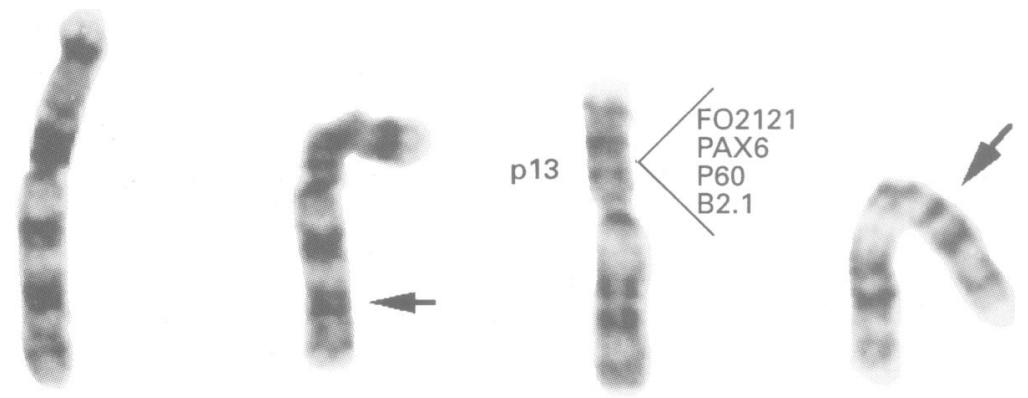

7

$\operatorname{der}(7)$

11

$\operatorname{der}(11)$

Figure 1 Partial karyotype of GTG banded chromosomes showing the normal and derived chromosomes 7 and 11. The breakpoints are indicated by arrows and the order of the probes within distal 11p13 is shown diagramatically. ridia, genitourinary anomalies, and mental retardation). Isolated aniridia can arise sporadically or segregate in an autosomal dominant fashion. The location of the gene was first suggested by the association of WAGR patients with cytogenetically visible interstitial deletions involving band $11 \mathrm{p} 13^{2}$ and by the cosegregation of dominant aniridia with structural chromosome rearrangements involving $11 \mathrm{p} 13 .^{3-5}$

Recent molecular studies have shown that PAX6, located within $11 \mathrm{p} 13$, was a strong candidate for the aniridia gene. ${ }^{6}$ Haploinsufficiency of PAX6 caused either by intragenic mutations ${ }^{7}$ or deletions ${ }^{89}$ have been described in both the sporadic and familial forms of aniridia and is thought to be the main mechanism underlying the phenotype. However, two exceptional dominantly inherited aniridia cases have recently been reported in which cosegregating structural chromosome abnormalities involving breakpoints within band $11 \mathrm{p} 13$ have been shown molecularly not to include the PAX6 locus or chromatin at least $85 \mathrm{~kb}$ distal to PAX6. ${ }^{10} \mathrm{We}$ present a third case of a child with sporadic aniridia and a balanced reciprocal translocation with an $11 \mathrm{p} 13$ breakpoint which, by FISH analysis, is shown not to involve PAX6.

\section{Materials and methods}

Standard PHA stimulated lymphocyte chromosome preparations were made from peripheral blood derived from the proband and her mother. The father is unavailable for study. Conventional cytogenetic analysis was carried out on 550 band metaphases. The four $11 \mathrm{p} 13$ cosmids used were kindly provided by $\mathrm{Dr} \mathrm{V}$ van Heyningen of the MRC Human Genetics Unit, Edinburgh, and telomere to centromere were: FO2121, FAT5 (PAX6), P60 (D11S324), B2.1 (WT1). ${ }^{11}$ The cosmid probes were labelled with digoxigenin using a Boehringer nick translation kit and FISH was carried out using a standard protocol with hybridisations carried out overnight at $37^{\circ} \mathrm{C}$. Following two five minute stringent washes in $1 \times \mathrm{SSC} / 50 \%$ formamide at $42^{\circ} \mathrm{C}$, visualisation of the cosmid signal was achieved by the application of a single layer of TRITC conjugated anti-digoxigenin (Boehringer). The alphoid repeat probes $\mathrm{p} 7 \mathrm{t} 1(\mathrm{D} 7 \mathrm{Z1})$ and $\mathrm{pLC} 11 \mathrm{~A}(\mathrm{D} 11 \mathrm{Z1})$ were directly labelled with fluorored and 

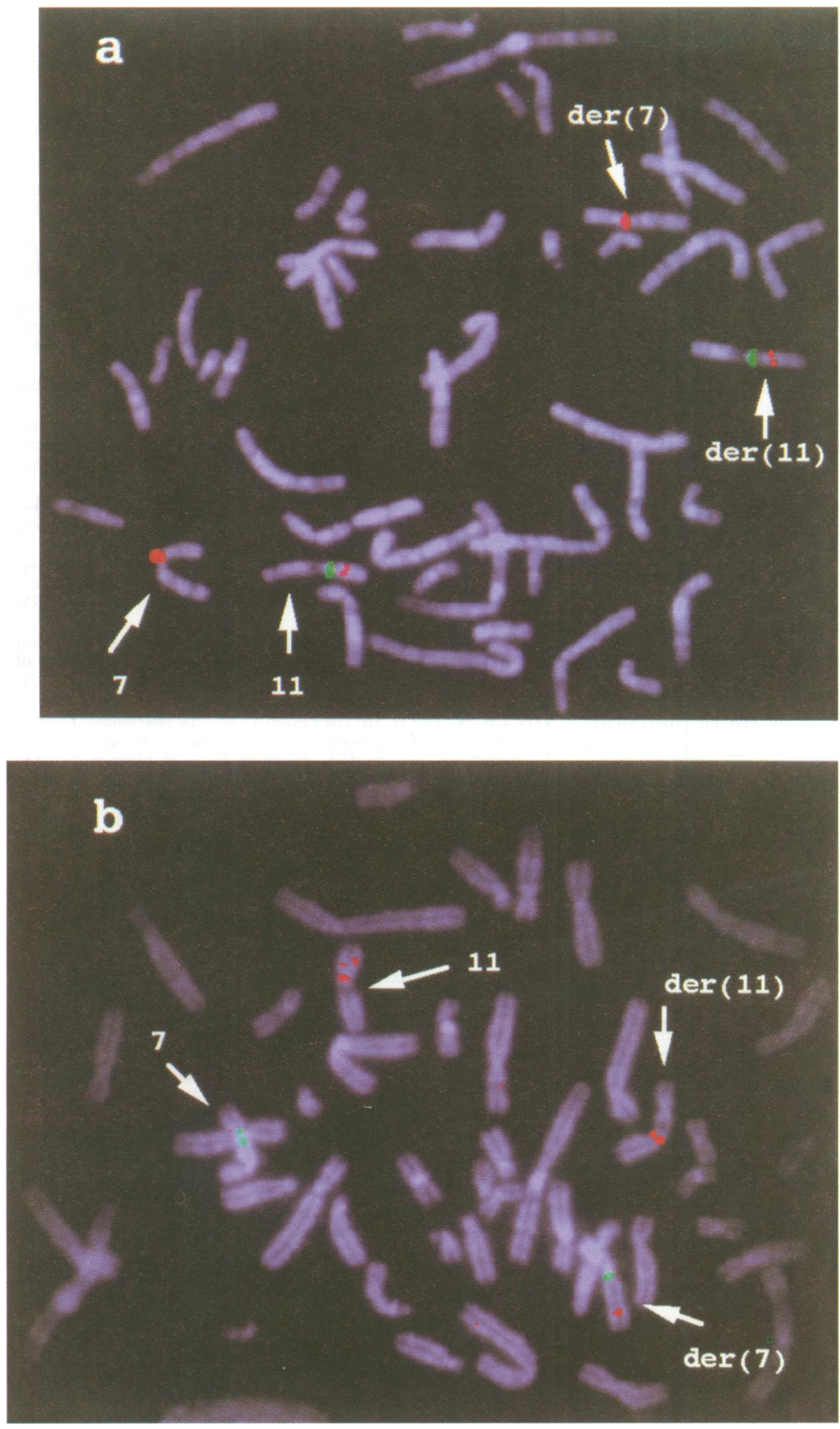

Figure 2 (a) Results of in situ hybridisation with the PAX6 cosmid, FAT5. The 11 centromeres are directly labelled with fluorogreen and the 7 centromeres with fluorored. The 11 p13 specific cosmid signal was detected using a single layer of TRITC conjugated antidigoxigen (Boehringer). Note that the FAT5 signal is present on both the normal and der(11)s. Cosmids P60 and B2.1 showed the same signal distribution (data not shown). (b) Results of in situ hybridisation with the cosmid FO2121 which maps approximately $100 \mathrm{~kb}$ telomeric to FAT5. The 11 centromeres are labelled directly with fluorored and the 7 centromeres with fluorogreen. Note that the red FO2121 signals can be seen on the normal 11 and on the der(7) respectively.

fluorogreen (Amersham). The chromosomes were counterstained with $0.05 \mathrm{mg} / \mathrm{ml}$ DAPI before analysis using a Zeiss Axiophot epifluorescent microscope, and images were observed using the Pinkel filter set and captured using a cooled CCD camera with Digital Scientific Smart Capture software. The normal and derivative chromosomes were identified by cohybridising the WAGR cosmids with the directly labelled alphoid centromere specific repeat probes.

\section{Case report}

The patient was born after an uneventful pregnancy at term (birth weight $2810 \mathrm{~g}$ ) to healthy, unrelated parents. At a few weeks of age the mother became concerned about the baby's sight and on examination she was found to have aniridia, but has at 3 years of age not developed any complications from her aniridia and her vision is apparently not severely affected. Her development is normal and a renal ultrasound scan showed no abnormalities.

The child's father, who is unavailable for further study, was described by the mother as having very bright blue eyes and there is no paternal family history of anyone with either visual problems or recurrent miscarriages.

\section{Conventional and molecular cytogenetic results}

Conventional cytogenetic studies showed that the proband has an apparently balanced reciprocal translocation between the long arm of chromosome 7 and the short arm of chromosome 11, 46, XX,t $(7 ; 11)$ (q31.2;p13)(fig 1). The mother's chromosomes are normal. FISH analysis showed that the most distal cosmid, FO2121, was present on the $\operatorname{der}(7)$, whereas the FAT5, P60, and B2.1 cosmids were all located on the der(11)(fig 2). This in situ hybridisation result is therefore: $46, \mathrm{XX}, \mathrm{t}(7 ; 11)$ (q31.2;p13).ish $\mathrm{t}(7 ; 11)(\mathrm{FO} 2121+$;FAT5 +, D11S324+,B2.1+). ${ }^{11 \mathrm{~A}}$

\section{Discussion}

The introduction of molecular cytogenetic techniques has led to the definition of a number of submicroscopic deletions associated with clinically defined phenotypes. Hemizygosity at $7 \mathrm{q} 11.23$ with deletions in the elastin gene giving rise to William's syndrome ${ }^{12}$ and a $2 \mathrm{Mb}$ deletion within 22q11 resulting in DiGeorge and related syndromes ${ }^{13}$ are two of the most frequently encountered examples. In the autosomal microdeletion syndromes so far described, functional hemizygosity for single or contiguous genes at the locus or loci defined by the probes used for the molecular diagnosis remains the most likely mechanism responsible for the respective phenotypes. ${ }^{14}$

A number of cases of dominant isolated aniridia segregating with apparently balanced reciprocal translocations or a cryptic paracentric inversion, all with an $11 \mathrm{p} 13$ breakpoint in common, have been reported. ${ }^{3-515}$ Two of these structural abnormalities, a $\mathrm{t}(4 ; 11)(\mathrm{q} 22 ; \mathrm{p} 13)$ known as SIMO $^{3}$ and a cryptic paracentric inversion in $11 \mathrm{p} 13$ known as SGL, ${ }^{15}$ have recently been studied at the molecular level by Fantes $e t a l^{10}$ using a combination of RT-PCR, pulse field gel electrophoresis, and detailed FISH analyses. It was concluded that the $11 \mathrm{p} 13$ breakpoints in SIMO and SGL were between $85 \mathrm{~kb}$ and $185 \mathrm{~kb}$ distal to PAX6, and, furthermore, no intragenic or open reading frame mutations of PAX6 were identified. These authors speculated that the aniridia phenotype was therefore caused by disruption of the chromatin domain distal to the PAX6 locus which 
in itself was sufficient to cause loss of function of the otherwise normal PAX6 resulting in functional haploinsufficiency for the aniridia gene. This therefore would be analogous to the "position effect" seen in Drosophila and yeast. ${ }^{1617}$

The case presented here would appear to support the aniridia position effect hypothesis suggested by Fantes et al. ${ }^{10}$ Although we cannot formally prove that our patient's translocation had arisen de novo, we do know that her mother's chromosomes are normal and that both her mother and father have normal vision. Our FISH studies suggest that the FAT5 cosmid (PAX6) is not involved in the translocation although at the level of resolution afforded by FISH, we cannot exclude the possibility that a breakpoint had occurred at the distal end of FAT $5^{18}$ and remained undetected with the techniques used.

Although, therefore, we have not formally shown that our patient does not have a concomitant intragenic PAX6 mutation, such an eventuality seems unlikely. The more plausible explanation, in keeping with the two previously reported cases, ${ }^{10}$ is that disruption of the chromatin domain distal to PAX6 is sufficient to produce the aniridia phenotype. A similar phenomenon has recently been described in three campomelic dysplasia patients with balanced reciprocal translocations involving $17 \mathrm{q}$ breakpoints which by molecular and FISH studies were shown to be between 50 to $100 \mathrm{~kb}$ from the SOX9 gene. ${ }^{19}$ Whether this mechanism is responsible for unmasking other human genetic diseases remains to be determined.

The authors are very grateful to $\mathrm{Mr}$ Peter Phelan, Consultant Ophthalmologist and Dr Michael Lowry, Consultant Paediatrician for referring this patient to us, and Drs Veronica van diatrician for referring this patient to us, and Drs Veronica van
Heyningen and Huntington Willard for the gifts of the cosmid and alphoid probes respectively.
1 van Heyningen V, Hastie ND. Wilms' tumour: reconciling genetics and biology. Trends Genet 1992;8:16-21.

2 Francke U, Holmes LB, Atkins L, Riccardi VM. AniridiaWilms' tumor association: evidence for specific deletion of 11p13. Cytogenet Cell Genet 1979;24:185-92.

3 Simola KOJ, Knuutila S, Kaitila I, Pirkola A, Pohja P. Familial aniridia and translocation $\mathrm{t}(4 ; 11)(\mathrm{q} 22 ; \mathrm{p} 13)$ withFamilial aniridia and translocation t(4;11)(q22;
out Wilms' tumor. Hum Genet 1983;63:158-61

4 Moore JW, Hyman S, Antonarakis SE, Mules EH, Thomas GH. Familial isolated aniridia associated with a translocation involving chromosomes 11 and $22[\mathrm{t}(11 ; 22)(\mathrm{p} 13$; q12.2)]. Hum Genet 1986;73:297-302.

5 Pettenati MJ, Weaver RG, Burton BK. Translocation $\mathrm{t}(5$; 11) (q13.1;p13) associated with familial isolated aniridia. Am $\mathcal{f}$ Med Genet 1989;34:230-2.

6 Ton CC, Hirvonen H, Miwa H, et al. Positional cloning and characterization of a paired box- and homeoboxcontaining gene from the aniridia region. Cell 1991;67: 1059-74.

7 Hanson IM, van Heyningen V. PAX6: more than meets the eye. Trends Genet 1995;11:268-72.

8 Fantes JA, Bickmore WA, Fletcher JM, Ballesta F, Hanson IM, van Heyningen V. Submicroscopic deletions at the WAGR locus, revealed by nonradioactive in situ hybridization. Am $\mathcal{F}$ Hum Genet 1992;51:1286-94.

9 Drechsler M, Meijers-Heijboer EJ, Schneider S, et al. Molecular analysis of aniridia patients for deletions involving the Wilms' tumor gene. Hum Genet 1994;94:331-8.

10 Fantes J, Redeker B, Breen M, et al. Aniridia-associated cytogenetic rearrangements suggest that a position effect may cause the mutant phenotype. Hum Mol Genet 1995; 4:415-22.

11 Fantes JA, Oghene K, Boyle S, et al. A high-resolution integrated physical, cytogenetic, and genetic map of human chromosome 11: distal p13 to proximal p15.1. Genomics 1995;25:447-61.

11A ISCN (1995). In: Mitelman F, ed. An international system for human cytogenetic nomenclature. Basel: Karger, 1995.

12 Ewart AK, Morris CA, Atkinson D, et al. Hemizygosity at the elastin locus in a developmental disorder, Williams the elastin locus in a developmental disc

13 Wilson DI, Burn J, Scambler P, Goodship J. DiGeorge syndrome: part of CATCH 22. F Med Genet 1993;30: 852-6.

14 Adinolfi $M$, Crolla JA. Nonisotopic in situ hybridization: clinical cytogenetics and gene mapping applications. In: Harris $\mathrm{H}$, Hirschhorn $\mathrm{K}$, eds. Advances in human genetics. New York: Plenum Press, 1995.

15 Fukushima Y, Hoovers J, Mannens M, et al. Detection of cryptic paracentric inversion within band $11 \mathrm{p} 13$ in familia aniridia by fluorescence in situ hybridization. Hum Genet 1993;91:205-9.

16 Karpen GH. Position-effect variegation and the new biology of heterochromatin. Curr Opin Genet Dev 1994;4:281-91.

17 Dillon N, Grosveld F. Chromatin domains as potential units of eukaryotic gene function. Curr Opin Genet Dev 1994; of eukaryotic

18 Jordan T, Hanson I, Zaletayev D, et al. The human PAX6 gene is mutated in two patients with aniridia. Nature Genet 1992;1:328-32.

19 Wagner T, Wirth J, Meyer J, et al. Autosomal sex reversal and campomelic dysplasia are caused by mutations in and around the $S R Y$-related gene SOX9. Cell 1994;79. 1111-20. 